\title{
In vitro Antioxidant Activity of Marine Diatoms
}

\author{
P. Karthikeyan ${ }^{1}$, K. Manimaran ${ }^{1}$, P. Sampathkumar ${ }^{1}$, M. Jaikumar ${ }^{2}$, R.S. Robin ${ }^{1}$ \\ C.Saravanakumar ${ }^{3}$ and C. Sureshkumar ${ }^{4}$ \\ ${ }^{1}$ Centre of Advanced Study in Marine Biology, Faculty of Marine Sciences, Annamalai University, \\ Parangipettai-608 502, India \\ ${ }^{2}$ Aquaculture Foundation of India, No.4/40. Kabaleswarer Nagar, Neelankarai, Chennai, 600 115, India \\ ${ }^{3}$ Applied Microbiology, PSG College of Arts \& Science, Coimbatore, 641 014, India \\ ${ }^{4}$ Institute for Ocean Management, Anna University, Chennai, 600 025, India
}

\begin{abstract}
The in vitro total antioxidant assay, total phenolic content, DPPH assay, FRAP assay of the acetone extracts from four centric diatoms (Chaetoceros simplex, Skeletonema costatum, Odontella mobiliensis, Coscinodiscus centralis) and three pennate diatoms (Nitzschia closterium, Pleurosigma angulatum and Navicula sp.) were performed. The centric diatom, O. mobiliensis was found higher amount of phenolic content $(0.75 \pm 0.06)$ followed by $C$. simplex. The maximum total antioxidant activity of $45.03 \pm 2.1$ ascorbic acid equivalent/g was observed in P. angulatum followed by the centric diatom C. simplex. The O. mobiliensis was showed significantly higher DPPH radical scavenging activity of $70.04 \pm 4.17 \%$ followed by C. simplex (55.69 $\pm 2.52 \%)$ and $P$. angulatum $(49.57 \pm 2.74 \%)$. The phenolic compounds of acetone extracts were not major contributor to the antioxidant capacities of these diatoms. The pigments such as, chlorophylls and carotenoids may be the main contributor of antioxidant activity in this study. The total antioxidant activity may be increased when extracted other solvent. Thus, these species can be act as natural antioxidant source for food preservation and protection of organisms from the degenerative diseases.
\end{abstract}

Keywords: Total Antioxidant activity, Marine diatoms, DPPH assay, FRAP assay, Total Phenolics.

\section{Introduction}

The oxidative damage caused by reactive oxygen species on lipids, proteins and nucleic acids may trigger various chronic diseases, such as coronary heart disease, atherosclerosis, cancer and ageing [1,2]. In recent years, there has been an explosive interest in the use of antioxidant nutritional supplements $[3,4]$.

Epidemiologic evidence has suggested that intake of some vitamins, minerals and other food constituents may help to protect the body against heart disease, cancer and the aging process and that antioxidants may have a protective effect in preventing these diseases or lessening their severity $[5,6]$. On the other hand, some synthetic antioxidants, such as BHT (butylated hydroxytoluene) and BHA (butylated hydroxyanisole) need to be replaced with natural antioxidants, as they were found to be toxic and carcinogenic in animal models $[7,8]$. Thus, it is important to identify new sources of safe and inexpensive antioxidants of natural origin.

The knowledge of the potential antioxidant compounds present in an organism is not always a good indicator of its antioxidant capacity. The interaction between different antioxidant compounds (termed synergism) means that the total antioxidant effect may be greater than the addition of the individual antioxidant activities. Thus, the study of an isolated compound will not offer an accurate picture of the overall action ability [9-11]. In addition, there are many different classes of antioxidant components in animal and plant tissues; and therefore, it is rather difficult to measure the activity of each antioxidant component separately. Thus, several analytical methods have been proposed to measure the total antioxidant activity of biological extracts so as to evaluate the total antioxidant capacity of biological samples [12-15].

The microalgae are good sources of natural antioxidants [16,17]. During the photosynthesis process they absorb solar light which is converted into chemical energy, later used in the conversion of $\mathrm{CO}_{2}$ into carbohydrates, lipids, and at the same time, generating molecular oxygen, which can reach locally high concentration levels. As, oxygen is easily activated by ultraviolet radiation (UV) or heat from sunlight into toxic reactive oxygen species (ROS), plants and microalgae have developed a protective mechanism which consists in the preparation of antioxidant compounds able to minimize the concentration of these ROS [18].

Large-scale microalgal production has been studied for decades $[19,20]$, given the wide variety of practical and potential metabolic products, such as food supplements, lipids, enzymes, biomass, polymers, toxins, pigments, tertiary wastewater treatment, and "green energy" products that can be obtained [21-23].

Although macroalgae have received much attention as potential natural antioxidants [24,25], there has been very limited information on antioxidant activity of microalgae [26,27]. Some studies reported that cancer was prevented by algal extracts [28], because of their antioxidant properties [29]. 
Microalgae represent an almost untapped resource of natural antioxidants, due to their enormous biodiversity, much more diverse than higher plants. The marine diatoms are contributing approximately $80 \%$ of total phytoplankton biomass. Number of species could be cultivated in laboratory and mass scale. Therefore, it was desirable to identify some rich sources of antioxidants from a large group of microalgae. The aims of this study were to identify new sources of safe and inexpensive antioxidants from selected marine diatoms.

\subsection{Algal culture and biomass}

\section{Materials and Methods}

The marine diatoms were isolated from Vellar estuary, Southeast coast of India by serial dilution and micro-pipette methods in Guillard's F/2 media. The stock cultures were maintained at $24 \pm 2{ }^{\circ} \mathrm{C}$ of temperature, $4500 \pm 500$ Lux of light intensity and $30 \mathrm{psu}$ of salinity. The mass cultivation was performed with $100 \mathrm{~L}$ glass tanks with $80 \mathrm{~L}$ of $\mathrm{F} / 2$ media. $1 \mathrm{~L}$ of exponentially grown culture of respective species was inoculated and cultured biomass was harvested by filtration of culture through bolting cloth filter bag. The biomass in the bag washed with pure seawater. The remaining water was drained by touching of plotting paper on outside surface of the filter bag. The biomass was transferred into $100 \mathrm{ml}$ glass beaker and lyophilized.

\subsection{Preparation of diatom extracts}

Dried finely powdered diatom samples $(1 \mathrm{~g})$ were extracted for $24 \mathrm{~h}$ in $10 \mathrm{ml}$ of acetone at room temperature under dark condition. Then the extraction was repeated twice and filtered through glass funnel and Whatmann No.1 filter paper. Each filtrate was concentrated to dryness.

\subsection{Chemicals and reagents}

2, 2-Diphenyl-1-picrylhydrazyl (DPPH) was purchased from Sigma-Aldrich. Gallic acid, Ascorbic acid, $\mathrm{FeCl}_{3}$, Trichloroacetic acid, Potassium ferricyanide, Vanillin, Folin Ciocalteus's phenol reagent, Sodium carbonate was from Merck (Mumbai, India). All the chemicals were of analytical grade.

\subsection{Total antioxidant activity}

Total antioxidant activities of crude extracts were determined according to the method of Prieto et al. [30]. Briefly, $0.3 \mathrm{~mL}$ of sample solution $(0.1 \mathrm{mg} / \mathrm{ml})$ was mixed with $3.0 \mathrm{~mL}$ reagent solution $(0.6 \mathrm{M}$ sulfuric acid, $28 \mathrm{mM}$ sodium phosphate and $4 \mathrm{mM}$ ammonium molybdate). Reaction mixture was incubated at $95^{\circ} \mathrm{C}$ for $90 \mathrm{~min}$ in a water bath. Absorbance of all the sample mixture was measured at $695 \mathrm{~nm}$. Total antioxidant activity is expressed as the number of equivalence of ascorbic acid. A calibration curve of ascorbic acid was prepared and the total antioxidant activity was standardized against ascorbic acid and was expressed as mg ascorbic acid equivalents per gram of sample on a dry weight (DW) basis.

\subsection{Determination of total phenolics}

The total phenolic content was estimated by the Folin-ciocalteu method [31]. Two hundred microlitres of the extract was mixed with $1 \mathrm{~mL}$ of Folin-Ciocalteu reagent (previously diluted with water 1:10 v/v). After 4 $\min , 800 \mu \mathrm{l}(75 \mathrm{~g} / \mathrm{L})$ of sodium carbonate was added. The tubes were vortexed for $15 \mathrm{sec}$ and allowed to stand for $2 \mathrm{hrs}$ at room temperature for colour development. Gallic acid was used for the standard calibration curve.

Absorbance was then measured at $765 \mathrm{~nm}$ using the PerkinElmer Lamda 25 UV-Vis Spectrophotometer. Total phenolic content was expressed as $\mathrm{mg} / \mathrm{g}$ Gallic acid equivalent.

\subsection{DPPH radical-scavenging activity}

The scavenging effects of samples for DPPH radical were monitored according to the method of Yen [32]. Briefly, a $2.0 \mathrm{ml}$ of aliquot of test sample was added to $2.0 \mathrm{ml}$ of $0.16 \mathrm{mM}$ DPPH methonolic solution. The mixture was vortexed for $1 \mathrm{~min}$ in the dark, and its absorbance was read at $517 \mathrm{~nm}$. The ability to scavenge the DPPH radical was calculated using the formulae given by Duan et al. [33] Synthetic antioxidants, Gallic acid and ascorbic acid were used as positive controls.

\subsection{Ferric reducing antioxidant power (FRAP) assay}

Reducing power of crude extract was determined by the method prescribed by Oyaizu [34]. Briefly, 1.0 $\mathrm{ml}$ of extract was mixed with $2.5 \mathrm{ml}$ of phosphate buffer $(0.2 \mathrm{M}, \mathrm{pH} 6.6)$ and $2.5 \mathrm{ml}$ potassium ferricyanide (1\%). Reaction mixture was incubated at $50{ }^{\circ} \mathrm{C}$ for $20 \mathrm{~min}$. After incubation, $2.5 \mathrm{ml}$ of trichloroacetic acid $(10 \%)$ was added and centrifuged $(650 \mathrm{~g})$ for $10 \mathrm{~min}$. From the upper layer, $2.5 \mathrm{ml}$ solution was mixed with 2.5 $\mathrm{mL}$ distilled water and $0.5 \mathrm{ml} \mathrm{FeCl} 3(0.1 \%)$. Absorbance of all the sample solutions was measured at $700 \mathrm{~nm}$.

Ascorbic acid is used as a positive control. FRAP value is expressed as the number of equivalence of gallic acid. 


\subsection{Statistical analysis}

Three replicates of each sample were used of statistical analysis and the values were reported as mean \pm SD. Pearson's correlation and One-way ANOVA with Duncan's multi-variant analysis were carried out using SPSS, version 16.0 software to study the relationship between antioxidant activities and total phenolic contents.

\section{Results}

The total phenolic contents of different centric and pennate diatoms are shown in Fig 1. When compared to other diatoms, the centric diatom, O. mobiliensis contain higher amount of phenol $(0.75 \pm 0.06)$ followed by $C$. simplex. Among the pennate diatoms, $N$. closterium and $P$. angulatum have higher quantity phenols. In this present study, the total antioxidant activities in the acetone extracts of diatoms are presented in Fig 2. In this phosphomolybdenum method, molybdenum VI $\left(\mathrm{Mo}^{6+}\right)$ is reduced to form a green phosphate/ $\mathrm{Mo}^{5+}$ complex. Higher activity of $45.03 \pm 2.1$ ascorbic acid equivalent/g was observed in $P$. angulatum followed by the centric diatom $C$. simplex having the activity of $31.13 \pm 1.9$ ascorbic acid equivalent/g. The acetone extracts of centric diatoms have the higher ability for reducing $\mathrm{Fe}^{3+}$ than pennate diatoms (Fig 3), which were similar to the results obtained in the total phenlic content. In this present study, DPPH radical scavenging activities (\%) of diatoms are presented in Fig 4. O. mobiliensis showed significantly higher activity of $70.04 \pm 4.17 \%$ followed by C. simplex $(55.69 \pm 2.52 \%)$ and $P$. angulatum $(49.57 \pm 2.74 \%)$.

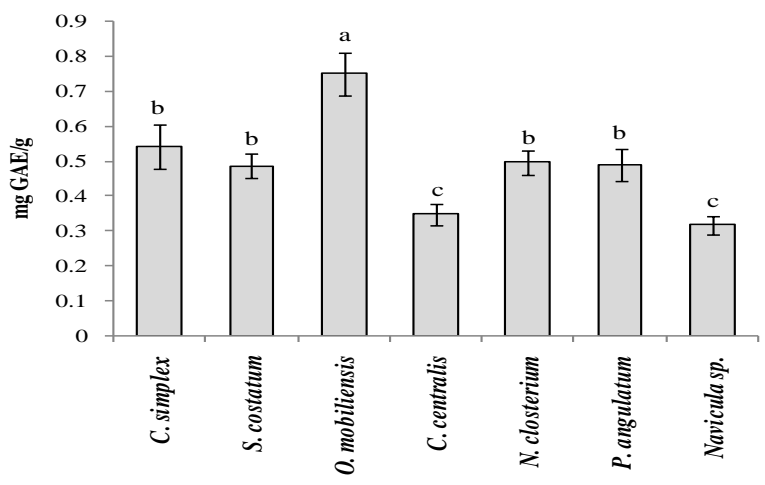

Fig 1. Total phenolic contents of different centric and pennate diatoms. Each value represents mean $\pm S D(n=3)$. Each species with different superscript letters are significantly different $(\mathrm{P} \leq 0.05)$.

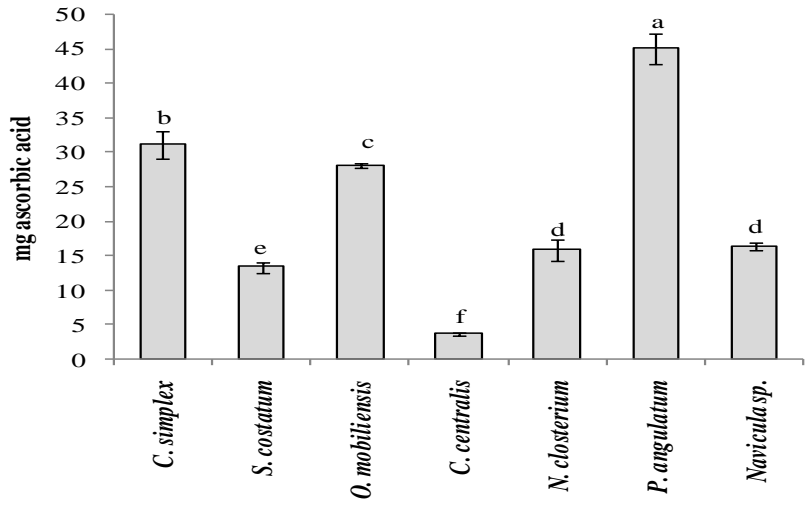

Fig 2. Total antioxidant activities of different centric and pennate diatoms. Each value represents mean \pm SD $(\mathrm{n}=3)$. Each species with different superscript letters are significantly different $(\mathrm{P} \leq 0.05)$. 


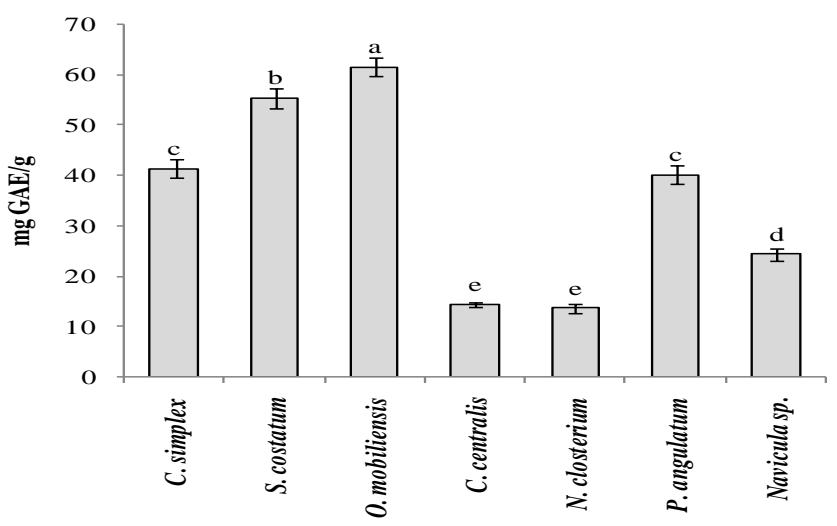

Fig 3. Ferric reducing antioxidant powers of different centric and pennate diatoms. Each value represents mean $\pm \mathrm{SD}(\mathrm{n}=3)$. Each species with different superscript letters are significantly different $(\mathrm{P} \leq 0.05)$.

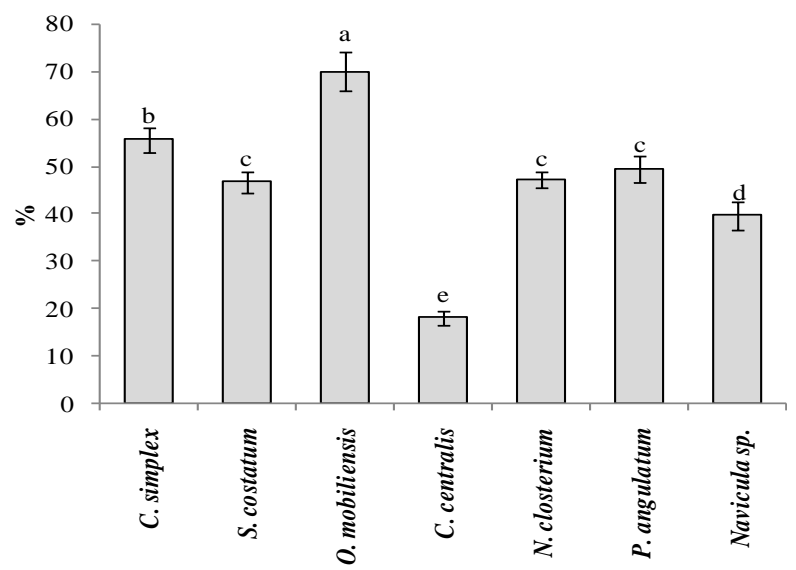

Fig 4. DPPH radical scavenging activities of different centric and pennate diatoms. Each value represents mean $\pm \mathrm{SD}(\mathrm{n}=3)$. Each species with different superscript letters are significantly different $(\mathrm{P} \leq 0.05)$.

Table 1. Correlation between Total phenolic content and antioxidant activity

\begin{tabular}{llll}
\hline & $\begin{array}{l}\text { Total Phenolic } \\
\text { Content }\end{array}$ & $\begin{array}{l}\text { Total Antioxidant } \\
\text { Activity }\end{array}$ & FRAP \\
\hline Total Antioxidant Activity & $0.459^{*}$ & & \\
FRAP & $0.702^{* *}$ & $0.463^{*}$ & \\
DPPH radical scavenging activity & $0.865^{* *}$ & $0.640^{* *}$ & $0.729^{* *}$ \\
\hline
\end{tabular}

* Correlation is significant at the 0.05 level (2-tailed).

** Correlation is significant at the 0.01 level (2-tailed).

As far as we know, there is no work have been investigated for the relationship between antioxidant activity and phenolic contents of different centric and pennate diatoms. In this study, four species from centric diatoms and three from pennate diatoms were evaluated for the first time, to establish the relationship between these two parameters. The correlation coefficient $\left(\mathrm{R}^{2}\right)$ between the antioxidant activities and total phenolic contents were determined and presented in Table 1 . The correlation coefficient between the total phenolic content and the antioxidant capacities was found to be small. The correlation between total phenolic content and total antioxidant activity $\left(R^{2}=0.459\right)$, DPPH assay $\left(R^{2}=0.865\right)$ and FRAP assay $\left(R^{2}=0.702\right)$. Similarly, small correlation was found between the Total antioxidant activity and DPPH assay (0.640) and the FRAP assay (0.463). Thus, the phenolic compounds were not major contributor to the antioxidant capacities of these diatoms.

\section{Discussion}

The lipid peroxidation is a reason for many degenerative diseases such as ageing, diabetes and cardiovascular disease. The food deterioration during processing and storage is also due to lipid perioxidation 
[35]. Antioxidants are playing major role on the inhibition of lipid peroxidation for food preservation and prevention of living cells against oxidative damage [36,37].

The phenolic compounds (phenolcarboxylic acids and their derivatives, catechols, flavonoids and carotenoids etc.) are considered to be major contributors of antioxidant capacity in microalgae [35]. These antioxidants also possess diverse biological activities, such as anti-inflammatory, anti-atherosclerotic and anticarcinogenic activities. These activities may be related to their antioxidant activity [38]. Thus, the total phenolic content of acetone extract of diatoms was evaluated, using the Folin-Ciocalteu method. The variation of phenolic content between species in this present study was quite large (Fig 1).

Microalgae have reported to contain carotenoids, vitamin E, phycocyanin, and chlorophyll [39]. These compounds are well known to decrease DPPH radicals by their hydrogen-donating ability [40-42]. The metalchelating activity is also widely used in evaluating the antioxidant activity of different natural products. Metal chelating activity is generally associated with the presence of reductones, which exert antioxidant action by breaking the free radical chains by donating a hydrogen atom. In this assay, the presence of reductants in the antioxidant sample causes the reduction of the $\mathrm{Fe}^{3+}$-ferricyanide complex to the $\mathrm{Fe}^{2+}$-ferrous form [43]. In the present study, the ferrous reducing antioxidant power of diatoms exhibited a strong reducing power as shown in Fig 3. It is probably due to the presence of antioxidant compounds that might act as electron donors. Similar results were reported by Bermejo et al. [44] and Gad et al. [45] in Spirulina.

In this study, the correlation co-efficient was showed the phenolic contents are lesser cause of antioxidant activity because the solvent used in this study was acetone. So it is assumed that the pigments are main element for the antioxidant, DPPH radical scavenging activity and FRAP. The microalgae have reported that the presence of pigments like chlorophylls and carotenoids. The antioxidant activity of carotenoids is based on the formation of radical adducts of carotenoids with free radicals derived from linoleic acid. The linoleic acid free radicals attack the highly unsaturated b-carotene models. In the presence of carotenoids, not only the free radical concentration becomes significantly lower, but there is also a reduction of $\mathrm{Fe}^{3+}$ to $\mathrm{Fe}^{2+}$ by carotenoids.

The presence of different antioxidants can hinder the extent of b-carotene bleaching by neutralising the linoleate-free radical and other free radicals formed in the system [46].

In conclusion, the antioxidant capacity and phenolic content of the seven diatoms were evaluated. $O$. mobiliensis and $P$. angulatum was found to have the highest antioxidant capacities and thus could be potential rich sources of natural antioxidants. The correlation coefficient between the antioxidant capacities and phenolic contents was very small, and phenolic compounds were not a major contributor to the antioxidant capacities of these diatoms. This was very different from many other plant species like vegetables, fruits, seaweeds and medicinal plants.

In this present study the Ferrous reducing antioxidant power and DPPH radical scavenging activity may be attributed due to its higher contents of proteins, lipids, and carbohydrates, elements such as zinc, magnesium, manganese, selenium, and some vitamins including b-carotene, riboflavin, cyanocobalamin, atocopherol, and a-lipoic acid.

\section{Acknowledgement:}

We thank to Prof. T. Balasubramanian, Dean, Faculty of Marine Sciences, Annamalai University, Parangipettai for provided the facilities to carry out the present work.

\section{References}

[1] Finkel T, Holbrook NJ. Oxidants, oxidative stress and the biology of ageing. Nature 2000; 408: $239-247$.

[2] Madhavi DL, Deshpande SS, Salunkhe DK. Food antioxidants: Technological, toxicological. Health perspective New York: Marcel Dekker 1996.

[3] Simpore J, Kabore F, Zongo F, Dansou D, Bere A, Pignatelli S, et al. Nutrition rehabilitation of undernourished children utilizing Spiruline and Misola. Nutr J 2006; 5:3-7.

[4] Gigante DP, Buchweitz M, Helbig E, Almeida AS, Araujo CL, Neumann NA, Victora C. Randomized clinical trial of the impact of a nutritional supplement "multimixture" on the nutritional status of children enrolled at preschools. J Pediatr 2007; 83:363-9.

[5] Wu LC, Ho JA, Shieh MC, Lu IW. Antioxidant and antiproliferative activities of Spirulina and Chlorella water extracts. J Agric Food Chem 2005; 53: 4207-12.

[6] Marcason W. Is supplementation of B vitamins still recommended to reduce the risk of heart disease? J Am Diet Assoc 2007; 107:525-31.

[7] Safer AM, Al-Nughamish AJ. Hepatotoxicity induced by the anti-oxidant food additive butylated hydroxytoluene (BTH) in rats: An electron microscopical study. Histology and Histopathology 1999; 14: 391-406.

[8] Rangasamy Ragupathi Raja Kannan, Arumugam R, Anantharaman P. In vitro antioxidant activities of ethanol extract from Enhalus acoroides (L.F.)Royle. Asian Pacific Journal of Tropical Medicine 2010; 898-901.

[9] Jia ZS, Zhou B, Yang L, Wu LM, Liu ZL. Antioxidant synergism of tea polyphenols and a-tocopherol against free radical induced peroxidation of linoleic acid in solution. Journal of the Chemical Society, Perkin Transactions 2: Physical Organic Chemistry 1998; 4: $911-15$

[10] Poeggeler B, Reiter RJ, Hardeland R, Sewerynek E, Melchiorri D, Barlow-Walden LR. Melatonin, a mediator of electron transfer and repair reactions, acts synergistically with the chainbreaking antioxidants ascorbate, trolox and glutathione. Neuroendocrinology Letters 1995; 17(2): 87-92. 
[11] Wu J, Sugiyama H, Zeng LH, Mickle D, Wu TW. Evidence of Trolox and some gallates as synergistic protectors of erythrocytes against peroxyl radicals. Biochemistry and Cell Biology 1998; 76(4): 661-64.

[12] Cano A, Hernandez-Ruiz J, Garcia-Canovas F, Acosta M, Arnao MB. An end-point method for estimation of the total antioxidant activity in plant material. Phytochemical Analysis 1998; 9(4): 196-202.

[13] Re R, Pellegrini N, Proteggente A, Pannala A, Yang M, Rice-Evans C. Antioxidant activity applying an improved ABTS radical cation decolorization assay. Free Radical Biology and Medicine 1999; 26(9/10): 1231-37.

[14] Wayner DDM, Burton GW, Ingold KU, Locke S. Quantitative measurement of the total, peroxyl radical-trapping antioxidant capability of human blood plasma by controlled peroxidation. The important contribution made by plasma proteins. FEBS Letters 1985; 187(1): $33-7$.

[15] Whitehead TP, Thorpe GHG, Maxwell SRJ. Enhanced chemiluminescent assay for antioxidant capacity in biological fluids. Analytica Chimica Acta 1992; 266(2): 265-77.

[16] Chkhikvishvili ID, Ramazanov ZM. Phenolic substances of brown algae and their antioxidant activity. Appl Biochem Microbiol 2000; 36: 289-91.

[17] Huang HL, Wang BG. Antioxidant capacity and lipophilic content of seaweeds collected from the Qingdao coastline. J Agricult Food Chem 2004; 52: 4993-97.

[18] Lu F, Foo LY. Phenolic antioxidant components of evening primrose. In ASH. Ong, E Niki, L Packer (Eds.), Nutrition, Lipids, Health, and Disease Champaign: American Oil Chemists Society 1995; pp. 86-95).

[19] Becker EW. Microalgae: Biotechnology and Microbiology. Cambridge University, Cambridge 1994; pp 293.

[20] Lee Y-K. Microalgal mass culture systems and methods: their limitation and potential. J Appl Phycol 2001; 3: 307-315.

[21] Lebeau T, Robert JM. Biotechnology of immobilized micro algae: a culture technique for the future? In: Rao S. (Ed.), Algal Cultures, Analogues of Blooms and Applications. Science Publishers, New Hampshire, USA 2006; pp 801-37.

[22] Harun R, Singh M, Forde GM, Danquah MK. Bioprocess engineering of microalgae to produce a variety of consumer products. Renew Sust Energ Rev 2010; 14: 1037-47.

[23] Karthikeyan P, Jayasudha S, Sampathkumar P, Manimaran K, Santhoshkumar C, Ashokkumar S, Ashokprabu V. Effect of Industrial Effluent on the Growth of Marine Diatom, Chaetoceros simplex (Ostenfeld, 1901). J Appl Sci Environ Manage 2010; 14(4): 35-7.

[24] Duan XJ, Zhang WW, Li XM, Wang BG. Evaluation of antioxidant property of extract and fractions obtained from a red alga, Polysiphonia urceolata. Food Chemistry 2006; 95: 37-43.

[25] Kuda T, Tsunekawa M, Hishi T, Araki Y. Antioxidant properties of dried 'kayamo-nori', a brown alga Scytosiphon lomentaria (Scytosiphonales, Phaeophyceae). Food Chemistry 2005; 89: 617-22.

[26] Miranda MS, Cintra RG, Barros SBM, Mancini-Filho J. Antioxidant activity of the microalga Spirulina maxima. Brazilian Journal of Medical and Biological Research 1998; 31: 1075-9.

[27] Murthy KNC, Vanitha A, Rajesha J, Swamy MM, Sowmya PR, Ravishankar GA. In vivo antioxidant activity of carotenoids from Dunaliella salina - a green microalga. Life Sciences 2005; 76: 1381-90.

[28] Schwartz J, Shklar G. Regression of experimental hamster cancer by betacarotene and alga extract. Journal of Oral and Maxillofacial Surgery 1987; 45: 510-5.

[29] Fedkovic Y, Astre C, Pinguet F, Gerber M, Ychou M, Pujol H. Spirulina and cancer. Bulletin de l'Institut Oceanographique 1993; 12: $117-20$.

[30] Prieto P, Pineda M, Aguilar M. Spectrophotometric quantification of antioxidant capacity through the formation of phosphomolybdenum complex: specific application to the determination of vitamin E. Anal Biochem 1999; 269:337-41.

[31] Singleton VL, Rossi JA. Colorimetry of total phenolics with phosphomolybdic-phosphotungstic acid reagents. American Journal of Enology and Viticulture 1965; 16: 144-153.

[32] Yen GC, Chen HY. Antioxidant activity of various tea extracts in relation to their antimutagenicity. J Agric Food Chem 1995; 43: 27-37.

[33] Duan XJ, Zhang WW, Li XM, Wang BG. Evaluation of Antioxidant property of extract and fractions obtained from a red alga, Polysiphonia urceolata. Food Chem 2006; 95: 37-43.

[34] Oyaizu M. Studies on product of browning reaction prepared from glucose amine. Jpn J Nutr 1986; 44: 307-15.

[35] Rodriguez-Garcia I, Guil-Guerrero JL. Evaluation of the antioxidant activity of three microalgal species for use as dietary supplements and in the preservation of foods. Food Chem 2008; 108: 1023-1026.

[36] Vimala S, Norhanom AW, Yadav M. Anti-tumour promoter activity in Malaysian ginger rhizobia used in traditional medicine. British Journal of Cancer 1999; 80(1-2): 110-116.

[37] Lorenz RT,Cysewski GR. Commercial potential for Haematococcus microalgae as a natural source of astaxanthin. Trends in Biotechnology 2000; 18(4): 160-167.

[38] Chung KT, Wong TY, Huang YW, Lin Y. Tannins and human health: a review. Critical Reviews in Food Science and Nutrition 1998; 38: 421-464.

[39] Nakaya N, Homma Y, Goto Y. Cholesterol lowering effect of Spiruline. Nutr Rep Int 1998; 37: 1329-37.

[40] Zhao M, Yang B, Wang J, Li B, Jiang Y. Identification of the major flavonoids from pericarp tissues of lychee fruit in relation to their antioxidant activities. Food Chem 2006; 98: 539-44.

[41] Duan X, Wu G, Jiang Y. Evaluation of the antioxidant properties of litchi fruit phenolics in relation to pericarp browning prevention. Molecules 2007; 12: 759-71.

[42] Li H, Wang X, Li Y, Li P, Wang H. Polyphenolic compounds and antioxidant properties of selected China wines. Food Chem 2009; 112: 454-60.

[43] Singh N, Rajini PS. Free radical scavenging activity of an aqueous extract of potato peel. Food Chem 2004; 85: 611-6.

[44] Bermejo P, Piñero E, Villar AM. Iron-chelating ability and antioxidant properties of phycocyanin isolated from a protean extract of Spirulina platensis. Food Chem 2008; 110: 436-45.

[45] Gad AS, Khadrawy YA, El-Nekeety AA, Mohamed SR, Hassan NS, Abdel-Wahhab MA. Antioxidant activity and hepatoprotective effects of whey protein and Spirulina in rats. Nutrition 2011; 27: 582-589.

[46] Jayaprakasha GK, Selvi T,Sakariah KK. Antibacterial and antioxidant activities of grape (Vitis vinifera) seed extracts. Food Research International 2003; 36(2): 117-122. 